\title{
Faktor Yang Memperingati Keaktifan Kunjungan Pos Pembinaan Terpadu Penyakit Tidak Menular (POSBINDU PTM) di Wilayah Kerja PUSKESMAS Baturube Kabupaten Morowali Utara Tahun 2020
}

\author{
Esti Anggara Puspa ${ }^{1}$, Nurhaedar Jafar ${ }^{1}$, Muh.Khidri Alwi ${ }^{1}$ \\ Pascasarjana Universitas Muslim Indonesia \\ *Email : anggarapuspa27@gmail.com
}

\begin{abstract}
Background : Indonesia has had problems over the last two decades triple burden diseases, that is diseases of infectious remains a big problem, incident re-emerging diseases and new emerging diseases and at the other hand the incidence of PTM tends to increase over time. Concerns on increased prevalence of PTM has led to the birth of agrement about global strategy in the prevention and control PTM. One of the efforts made in the form of Posbindu PTM. This research aims to find out the factors that influence the activeness of the visit of integrated construction post of uncommunicable diseases (Posbindu PTM) in the working area of Baturube Health Center north Morowali regency. Method : The research in quantitative with the approach of cross sectional. The technique of the sample collection is done with the way purposive sampling of the total sample 127 respondents. An analysis of data using the Analyze the Chi Square. The result : Of output $t$ count for knowledge of 2.327 the significance value is $0.022(\mathrm{sig}<0.05)$, the distance is 2.580 the significance value is 0.011 ( $\mathrm{sig}<0.05$ ), with the cadres support of 4.042 the significance value is $0.000(\mathrm{sig}<0.05)$, family support is 4.926 the significance value is $0.000(\mathrm{sig}<0.05)$. The conclusions : in this study show there is a significant influence between knowledge, distance, support of cadres and family support on the activeness of visits of integrated construction posts of uncommunicable diseases (Posbindu PTM) in the working area of Baturube Health Center north Morowali Regency.
\end{abstract}

Keywords : Posbindu, Active Visitation, Uncommunicable Diseases 


\begin{abstract}
ABSTRAK
Latar Belakang : Indonesia dalam beberapa dasawarsa terakhir menghadapi masalah triple burden diseases, yaitu penyakit menular yang masih menjadi masalah, kejadian re-emerging diseases, dan new emerging diseases dan disisi lain kejadian PTM cenderung meningkat dari waktu ke waktu. Keprihatinan terhadap peningkatan prevalensi PTM telah mendorong lahirnya kesepakatan tentang strategi global dalam pencegahan dan pengendalian PTM, salah satu upaya yang dilakukan berupa posbindu PTM. Tujuan dalam penelitian ini yaitu untuk mengetahui faktor yang mempengaruhi keaktifan kunjungan pos pembinaan terpadu penyakit tidak menular (Posbindu PTM) di wilayah kerja Puskesmas Baturube kabupaten Morowali Utara. Metode : Penelitian ini merupakan penelitian Kuantitatif dengan pendekatan Cross Sectional. Teknik pengambilan sampel dilakukan dengan cara Purposive Sampling dengan jumlah sampel 127 responden. Analisis data menggunakan uji Chi Square. Hasil : Dari hasil output $t$ hitung untuk pengetahuan sebesar 2.327 dengan nilai signifikansi $0.022(\operatorname{sig}<0,05)$, jarak sebesar 2.580 dengan nilai signifikansi 0.011 ( $\mathrm{sig}<0,05)$, dukungan kader sebesar 4.042 dengan nilai signifikansi 0.000 (sig<0,05), dukungan keluarga sebesar 4.926 dengan nilai signifikansi 0.000 (sig<0,05). Kesimpulan : Penelitian ini menunjukan Adanya pengaruh yang signifikan antara pengetahuan, jarak, dukungan kader dan dukungan keluarga terhadap keaktifan kunjungan pos pembinaan terpadu penyakit tidak menular (Posbindu PTM) di wilayah kerja Puskesmas Baturube Kabupaten Morowali Utara.
\end{abstract}

Kata Kunci : Posbindu, Keaktifan Kunjungan, Penyakit Tidak Menular

\section{LATAR BELAKANG}

Indonesia dalam beberapa dasawarsa terakhir menghadapi masalah triple burden diseases, yaitu penyakit menular yang masih menjadi masalah, kejadian reemerging diseases dan new emerging diseases yang masih sering terjadi, dan di sisi lain kejadian PTM cenderung meningkat dari waktu ke waktu. Hal ini terjadi akibat gaya hidup tidak sehat, yang dipacu oleh urbanisasi, modernisasi dan globalisasi. Bertambahnya usia harapan hidup sejalan dengan perbaikan sosioekonomi dan pelayanan kesehatan, membawa konsekuensi peningkatan penyakit tidak menular (Kemenkes RI, 2012).

Riskesdas tahun 2018 menunjukkan bahwa terjadi peningkatan pada indikatorindikator kunci PTM yang tercantum dalam RPJM 2015-2019 yaitu prevalensi tekanan darah tinggi pada penduduk usia >
18 tahun meningkat dari $25,8 \%$ menjadi $34,1 \%$, prevalensi obesitas penduduk usia $>18$ tahun meningkat dari $14,8 \%$ menjadi $21,8 \%$ dan prevanlensi merokok penduduk $<18$ tahun meningkat dari 7,2\% menjadi 9,1\% (Kemenkes RI, 2019).

Keprihatinan terhadap peningkatan prevalensi PTM telah mendorong lahirnya kesepakatan tentang strategi global dalam pencegahan dan pengendalian PTM, khususnya dinegara berkembang. PTM telah menjadi isu strategis dalam SDGs 2030 sehingga harus menjadi prioritas pembangunan di setiap negara yang memerlukan penanganan lintas sektor.

Berbagai upaya telah dilakukan untuk pencegahan dan penanggulangan PTM, sejalan dengan pendekatan WHO terhadap penyakit PTM utama yang terkait dengan faktor risiko bersama (Common Risk Factors). Indikator Program Pencegahan dan Pengendalian Penyakit Tidak Menular (P2PTM) dengan tujuan 
SDGs (Sustanaible Development Goals) yaitu mengurangi hingga sepertiga angka kematian dini akibat penyakit tidak menular pada tahun 2030. Upaya tersebut di antaranya yaitu program Pengendalian terpadu penyakit tidak menular (PANDU PTM), Pos pembinaan terpadu penyakit tidak menular (Posbindu PTM), Deteksi dini kanker serviks dan payudara, Kawasan tanpa rokok (KTR), Deteksi dini dan rujukan katarak (Kemenkes RI, 2019).

Posbindu PTM merupakan wujud peran serta masyarakat dalam melakukan kegiatan deteksi dini dan monitoring faktor risiko PTM serta tindak lanjutnya yang dilaksanakan secara terpadu, rutin, dan periodik. Kegiatan Posbindu PTM diharapkan dapat meningkatkan sikap mawas diri masyarakat terhadap faktor risiko PTM sehingga peningkatan kasus PTM dapat dicegah. Sikap mawas diri ini menunjukkan dengan adanya perubahan perilku masyarakat yang lebih sehat dan pemanfaatan fasilitas pelayanan kesehatan tidak hanya pada saat sakit, melainkan juga pada keadaan sehat (Kemenkes RI, 2014).

Berdasarkan hasil studi pendahuluan di Posbindu PTM Desa Bulupitu, keaktifan masyarakat untuk melakukan kunjungan Posbindu PTM perbulan masih rendah. Hasil wawancara dari 5 responden, 2 orang menyatakan bahwa lebih baik tidak mengetahui penyakitnya dari pada akan menjadikan pikiran, sedangkan 1 orang lainnya mengatakan kadang-kadang mengikuti Posbindu kalau mengetahui jadwalnya, dan 2 orang menyatakan rutin datang mengikuti kegiatan Posbindu setiap bulan karena merasakan manfaatnya yaitu mengetahui keadaan kesehatannya (Rusdiyanti, 2017).

Inisiasi keterlibatan masyarakat dimulai pada tahun 2011 dengan pendekatan per area, melalui satu Posbindu PTM setiap desa. Jumlah Posbindu PTM di Indonesia menurut Profil Kesehatan Indonesia tahun 2016 yaitu 21.470 Posbindu PTM. Secara nasional desa/kelurahan yang melaksanakan kegiatan Posbindu PTM hanya sebesar $(14,85 \%)$. Persentase ini masih dibawah target Rencana Strategis kementerian Kesehatan tahun 2016 yaitu sebesar 20\% (Ika Mardhiyanti, 2019).

Data jumlah Pobindu PTM di Provinsi Sulawesi Tengah tahun 2018 yaitu sebanyak 1.378 Posbindu yang tersebar di 13 kabupaten, dan Kabupaten Morowali Utara memiliki 142 Posbindu PTM. Data dari Dinas Kesehatan Morowali Utara, terdapat 10 puskesmas di wilayah kerja Kabupaten Morowali Utara, salah satunya yaitu Puskesmas Baturube. Dengan jumlah penduduk 15-50 tahun sebanyak 8.281 jiwa dan jumlah wanita 30-50 tahun sebanyak 3.581 jiwa serta terdapat 14 posbindu. Posbindu PTM diwilayah kerja Puskesmas Baturube telah berdiri sejak tahun 2018 namun aktif pada tahun 2019 dengan jumlah kunjungan usia $>15$ tahun sebanyak 4.949 jiwa $(41,7 \%)$, namun mempunyai cakupan kegiatan Posbindu PTM yang jauh dari target yang telah ditetapkan $(100 \%)$ yaitu berada dibawah $46 \%$ pada tahun 2018. Permasalahan tersebut dapat disebabkan oleh berbagai faktor yang terdapat pada input dan proses pelaksanaan kegiatan Posbindu PTM. Konfirmasi terkait penyebab masalah tersebut dapat diketahui jawabannya melalui penelitian terhadap faktor keaktifan kunjungan kegiatan Posbindu PTM di wilayah kerja Puskesmas Baturube.

Berdasarkan latar belakang tersebut, peneliti tertarik untuk melakukan 
penelitian dengan judul " Analisis Faktor yang Mempengaruhi Keaktifan Kunjungan Pos Pembinaan Terpadu Penyakit Tidak Menular (Posbindu PTM) di wilayah Kerja Puskesmas Baturube Kebupaten Morowali Utara".

\section{METODE}

Penelitian ini merupakan penelitian kuantitatif dengan menggunakan desain cross sectional study yaitu penelitian untuk mempelajari dinamika korelasi antara faktor risiko terhadap efek, dengan cara pendekatan, observasi atau pengumpulan data sekaligus pada suatu saat, dimana data variabel dependen (keaktifan kunjungan posbindu PTM) dan variabel independen (faktor yang mempengaruhi keaktifan kunjungan posbindu PTM yang meliputi : pengetahuan, jarak, perilaku petugas kesehatan, dukungan kader dan dukungan keluarga,) diukur/diobservasi dalam waktu yang bersamaan pada setiap responden dengan menggunakan instrument penelitian berupa kuisioner yang telah validitas serta realibilitasnya telah teruji (Nursalam, 2014 dalam Ivong R, 2017). Populasi dalam penelitian ini adalah seluruh masyarakat yang melakukan kunjungan di Posbindu PTM di wilayah kerja Puskesmas Baturube tahun 2019 dengan usia $\geq 15$ tahun yang berjumlah 324 jiwa. Teknik pengambilan sampel dalam penelitian ini adalah purposive sampling dengan jumlah sampel sebanyak 127 sampel.

\section{HASIL}

\section{Analisis Univariat}

Tabel 1. Distribusi Karakteristik Responden di wilayah kerja Puskesmas Baturube Kabupaten Morowali Utara

\begin{tabular}{lccc}
\hline \multicolumn{1}{c}{ Karakteristik Responden } & \multicolumn{3}{c}{ Keaktifan kunjungan } \\
\cline { 2 - 4 } Jenis kelamin & Tidak aktif & Aktif & Total \\
Laki-laki & 17 & 9 & 26 \\
Perempuan & $65.4 \%$ & $34.6 \%$ & $100 . \%$ \\
Umur (Tahun) & 64 & 37 & 101 \\
15-25 (Remaja & $63.4 \%$ & $36.6 \%$ & $100 . \%$ \\
26-45 (Dewasa) & & & \\
& 6 & 2 & 8 \\
46-65 (Lansia) & $75.0 \%$ & $25.0 \%$ & $100 . \%$ \\
& 51 & 33 & 84 \\
>65 (Manula) & $60.7 \%$ & 39.3 & $100 . \%$ \\
Pekerjaan & 20 & 11 & 31 \\
IRT & $64.5 \%$ & 35.5 & $100 . \%$ \\
& 4 & 0 & 4 \\
PNS & $100.0 \%$ & & $100 . \%$ \\
& & & \\
& 47 & 27 & 74 \\
& $63.5 \%$ & $36.5 \%$ & $100 . \%$ \\
& 4 & 1 & 5 \\
& $60.0 \%$ & & $100 . \%$
\end{tabular}




\begin{tabular}{|c|c|c|c|}
\hline Wiraswasta & $\begin{array}{c}7 \\
58.3 \%\end{array}$ & $\begin{array}{c}5 \\
41.7 \%\end{array}$ & $\begin{array}{c}12 \\
100 \%\end{array}$ \\
\hline Petani & $\begin{array}{c}15 \\
65.2 \%\end{array}$ & $\begin{array}{c}8 \\
34.8 \%\end{array}$ & $\begin{array}{c}23 \\
100 . \%\end{array}$ \\
\hline Nelayan & $\begin{array}{c}8 \\
61.5 \%\end{array}$ & $\begin{array}{c}5 \\
38.5 \%\end{array}$ & $\begin{array}{c}13 \\
100 . \%\end{array}$ \\
\hline Pendidikan & & & \\
\hline Tidak Sekolah & $\begin{array}{c}8 \\
61.5 \%\end{array}$ & $\begin{array}{c}5 \\
38.5 \%\end{array}$ & $\begin{array}{c}13 \\
100 . \%\end{array}$ \\
\hline SD & $\begin{array}{c}20 \\
64.5 \%\end{array}$ & $\begin{array}{c}11 \\
35.5 \%\end{array}$ & $\begin{array}{c}31 \\
100 . \%\end{array}$ \\
\hline SMP & $\begin{array}{c}29 \\
63.0 \%\end{array}$ & $\begin{array}{c}17 \\
37.0\end{array}$ & $\begin{array}{c}46 \\
100 . \%\end{array}$ \\
\hline SMA & $\begin{array}{c}18 \\
69.2 \%\end{array}$ & $\begin{array}{c}8 \\
30.8 \%\end{array}$ & $\begin{array}{c}26 \\
100 . \%\end{array}$ \\
\hline D3/S1 & $\begin{array}{c}6 \\
54.5 \%\end{array}$ & $\begin{array}{c}5 \\
45.5 \%\end{array}$ & $\begin{array}{c}11 \\
100 . \%\end{array}$ \\
\hline Riwayat Penyakit & & & \\
\hline Tidak menderita PTM & $\begin{array}{c}44 \\
63.8\end{array}$ & $\begin{array}{c}25 \\
36.2\end{array}$ & $\begin{array}{c}69 \\
100 . \%\end{array}$ \\
\hline Menderita 1 PTM & $\begin{array}{c}27 \\
64.3 \%\end{array}$ & $\begin{array}{c}15 \\
35.7 \%\end{array}$ & $\begin{array}{c}42 \\
100 . \%\end{array}$ \\
\hline Menderita >1 PTM & $\begin{array}{c}10 \\
62.5 \%\end{array}$ & $\begin{array}{c}6 \\
37.5 \%\end{array}$ & $\begin{array}{c}16 \\
100 \%\end{array}$ \\
\hline
\end{tabular}

Sumber: Data primer Tahun 2020

Untuk kategori jenis kelamin terbanyak adalah perempuan sebanyak 101 sampel, yang tidak aktif melakukan kunjungan sebanyak 64 sampel (63.4\%) yang aktif sebanyak 37 sampel (36.6\%) dan laki-laki sebanyak 26 sampel yang tidak aktif melakukan kunjungan sebanyak 17 sampel (65.4\%) yang aktif sebanyak 9 sampel (34.6\%), Untuk kategori umur berdasarkan Depkes 2009, proporsi umur sampel terbanyak yaitu kategori dewasa 2645 tahun sebanyak 84 sampel yang tidak aktif melakukan kunjungan sebanyak 51 sampel (60.7\%) yang aktif sebanyak 33 sampel (39.3\%), Pekerjaan terbanyak adalah IRT (ibu rumah tangga) sebanyak 74 sampel yang tidak aktif melakukan kunjungan sebanyak 47 sampel (63.5\%) yang aktif sebanyak 27 sampel (36.5\%), Pendidikan terbanyak sampel adalah SMP sebanyak 46 sampel yang tidak aktif melakukan kunjungan sebanyak 29 sampel (63.0\%) yang aktif sebanyak 17 sampel (37.0\%), dan untuk kategori riwayat penyakit sebanyak 69 sampel tidak menderita penyakit tidak menular (PTM) yang tidak aktif melakukan kunjungan sebanyak 44 sampel (63.8\%) yang aktif sebanyak 25 sampel (36.2\%), dari 42 sampel yang menderita salah satu penyakit tidak menular (PTM) yang tidak aktif melakukan kunjungan sebanyak 27 sampel (64.3\%) yang aktif sebanyak 15 sampel (35.7\%) dan dari 16 sampel yang menderita lebih dari satu penyakit tidak menular (PTM) yang tidak aktif melakukan kunjungan sebanyak 10 sampel (62.5\%) yang aktif sebanyak 6 sampel (37.5\%). 
Tabel 2. Distribusi variabel-variabel bebas dan keaktifan kunjungan Posbindu PTM di wilayah kerja Puskesmas Baturube Kabupaten Morowali Utara

\begin{tabular}{llll}
\hline Variabel & Kategori & n & \% \\
\hline Pengetahun & Kurang & 82 & 64.6 \\
& Cukup & 28 & 22.0 \\
& Baik & 17 & 13.4 \\
Jarak & Jauh & 104 & 81.9 \\
& Dekat & 23 & 18.1 \\
& & & \\
Perilaku & Kurang & 10 & 7.9 \\
petugas & Cukup & 117 & 92.1 \\
kesehatan & & & \\
$\begin{array}{l}\text { Dukungan } \\
\text { Kader }\end{array}$ & Kurang & 81 & 63.8 \\
& Cukup & 46 & 36.2 \\
$\begin{array}{l}\text { Dukungan } \\
\text { Keluarga }\end{array}$ & Kurang & 85 & 66.9 \\
& Cukup & 42 & 33.1 \\
Keaktifan & & & \\
Kunjungan & Tidak Aktif 81 & 63.8 \\
\hline
\end{tabular}

\section{Analisis Bivariat}

Tabel 3. Pengaruh Pengetahuan dengan Keaktifan Kunjungan Posbindu PTM di wilayah kerja Puskesmas Baturube

\begin{tabular}{lcccc}
\hline Pengeta & \multicolumn{4}{c}{ Keaktifan Kunjungan } \\
\cline { 2 - 5 } huan & $\begin{array}{c}\text { Tidak } \\
\text { aktif }\end{array}$ & Aktif & Total & $\boldsymbol{p}$. \\
\hline Kurang & 68 & 14 & 82 & \\
& $82.9 \%$ & $17.1 \%$ & $100.0 \%$ & \\
\hline
\end{tabular}

$\begin{array}{ccccc}\text { Sedang } & 8 & 20 & 28 & 0.000 \\ & 28.6 \% & 71.4 \% & 100.0 \% & \\ \text { Cukup } & 5 & 12 & 17 & \\ & 29.4 \% & 70.6 \% & 100.0 \% & \end{array}$

$\begin{array}{llll}\text { Total } & 81 & 46 & 127\end{array}$

Sumber: Data primer Tahun 2020 \begin{tabular}{ccc} 
Aktif & 46 & 36.2 \\
\hline Sumber : Data Primer Tahun 2020
\end{tabular}

Berdasarkan hasil penelitian terhadap 127 responden diketahui bahwa responden yang berpengetahuan kurang sebanyak 82 responden (64.6\%), Jarak tempuh ke tempat pelaksanaan Posbindu PTM yang jauh sebanyak 104 responden $(81.9 \%)$ dan dekat sebanyak 23 responden (18.1\%), Perilaku petugas kesehatan kategori baik sebanyak 117 responden (92.1\%), Untuk variabel dukungan kader kesehatan terbanyak adalah kategori kurang yaitu sebanyak 81 responden $(63.8 \%)$ dan cukup sebanyak 46 responden (36.2\%), Dukungan keluarga terhadap responden kurang yaitu sebanyak 85 responden (66.9\%), dan keaktifan kunjungan responden dalam penelitian ini terbanyak yang tidak aktif yaitu sebanyak 81 responden $(63.8 \%)$ dan aktif sebanyak 46 responden $(36.2 \%)$.

Berdasarkan hasil penilaian pengaruh antara pengetahuan dengan keaktifan kunjungan Posbindu PTM di wilayah kerja Puskesmas Baturube bahwa dari 17 responden yang memiliki pengetahuan baik, yang tidak aktif melakukan kunjungan sebanyak 5 responden (29.4\%) dan yang aktif melakukan kunjungan sebanyak 12 responden $70.6 \%$ ), pada 28 responden yang memiliki pengetahuan cukup, yang tidak aktif melakukan kunjungan sebanyak 8 responden $(28.6 \%)$ dan yang aktif melakukan kunjungan sebanyak 20 responden $(71.4 \%)$ dan dari 82 responden yang memiliki pengetahuan kurang, yang tidak aktif melakukan kunjungan sebanyak 68 responden $(82.9 \%)$ 
dan 14 responden (17.1\%) yang aktif melakukan kunjungan. Hasil uji bivariat dengan menggunakan uji chi square dengan alternative Uji fisher menunjukan bahwa nilai $\mathrm{p}=0,000<0,05$ yang artinya ada

Tabel 4. Pengaruh Jarak dengan Keaktifan Kunjungan Posbindu PTM di wilayah kerja Puskesmas Baturube

\begin{tabular}{lcccc}
\hline Jarak & \multicolumn{4}{c}{ Keaktifan Kunjungan } \\
\cline { 2 - 5 } & $\begin{array}{c}\text { Tidak } \\
\text { aktif }\end{array}$ & Aktif & Total & $\boldsymbol{p .}$ \\
\hline Jauh & 77 & 27 & 104 & \\
& $74.0 \%$ & $26.0 \%$ & $100.0 \%$ & \\
\hline
\end{tabular}

$\begin{array}{ccccc}\text { Dekat } & 4 & 19 & 23 & 0.000 \\ & 17.4 \% & 82.6 \% & 100.0 \% & \end{array}$

$\begin{array}{llll}\text { Total } & 81 & 46 & 127\end{array}$

$\begin{array}{lll}63.8 \% & 36.2 \% & 100.0 \%\end{array}$

Sumber: Data primer Tahun 2020

Berdasarkan hasil penilaian pengaruh antara jarak dengan keaktifan kunjungan Posbindu PTM di wilayah kerja Puskesmas Baturube bahwa dari 104 responden yang menempuh jarak jauh yang tidak aktif melakukan kunjungan sebanyak 77 responden (74.0\%) dan yang aktif melakukan kunjungan dengan jarak yang jauh sebanyak 27 responden $(26.0 \%)$, pada 23 responden yang jarak ke tempat pelaksanaan kegiatan Posbindu PTM dekat namun tidak aktif melakukan kunjungan sebanyak 4 responden (17.4\%) sedangkan yang aktif melakukan kunjungan sebanyak 19 responden $(82.6 \%)$. Hasil uji bivariat dengan menggunakan uji chi square dengan alternative Uji fisher menunjukan bahwa nilai $\mathrm{p}=0,000<0,05$ yang artinya ada hubungan yang signifikan antara jarak dengan keaktifan kunjungan Posbindu PTM di wilayah kerja Puskesmas Baturube pengaruh yang signifikan antara pengetahuan dengan keaktifan kunjungan Posbindu PTM di wilayah kerja Puskesmas Baturube.

Tabel 5. Pengaruh Dukungan Kader dengan Keaktifan Kunjungan Posbindu PTM di wilayah kerja Puskesmas Baturube

\begin{tabular}{|c|c|c|c|c|}
\hline \multirow{2}{*}{$\begin{array}{r}\text { Dukunga } \\
\text { n kader }\end{array}$} & \multicolumn{4}{|c|}{ Keaktifan Kunjungan } \\
\hline & $\begin{array}{l}\text { Tidak } \\
\text { aktif }\end{array}$ & Aktif & Total & $p$. \\
\hline Kurang & $\begin{array}{c}68 \\
84.0 \%\end{array}$ & $\begin{array}{c}13 \\
16.0 \%\end{array}$ & $\begin{array}{c}81 \\
100.0 \%\end{array}$ & \\
\hline Cukup & $\begin{array}{c}13 \\
28.3 \%\end{array}$ & $\begin{array}{c}33 \\
71.7 \%\end{array}$ & $\begin{array}{c}46 \\
100.0 \%\end{array}$ & 0.000 \\
\hline Total & $\begin{array}{c}81 \\
63.8 \%\end{array}$ & $\begin{array}{c}46 \\
36.2 \%\end{array}$ & $\begin{array}{c}127 \\
100.0 \%\end{array}$ & \\
\hline
\end{tabular}

Berdasarkan hasil penilaian pengaruh antara dukungan kader kesehatan dengan keaktifan kunjungan Posbindu PTM di wilayah kerja Puskesmas Baturube bahwa dari 81 responden dengan dukungan kader yang kurang yang tidak aktif melakukan kunjungan sebanyak 68 responden $(84.0 \%)$ dan yang aktif melakukan kunjungan sebanyak 13 responden (16.0\%), sedangkan pada 46 responden dengan dukungan kader kesehatan yang cukup yang tidak aktif melakukan kunjungan sebanyak 13 responden (28.3\%) dan yang aktif melakukan kunjungan sebanyak 33 responden (71.7\%). Hasil uji bivariat dengan menggunakan uji chi square dengan alternative Uji fisher menunjukan bahwa nilai $\mathrm{p}=0,000<0,05$ yang artinya ada hubungan yang signifikan antara dukungan kader kesehatan dengan keaktifan kunjungan Posbindu PTM di wilayah kerja Puskesmas Baturube. 
Tabel 6. Pengaruh Dukungan Keluarga dengan Keaktifan Kunjungan Posbindu PTM di wilayah kerja Puskesmas Baturube
Tabel 7. Pengaruh Perilaku Petugas Kesehatan dengan Keaktifan Kunjungan Posbindu PTM di wilayah kerja Puskesmas Baturube

\begin{tabular}{lcccc}
\hline Dukungan & \multicolumn{4}{c}{ Keaktifan Kunjungan } \\
\cline { 2 - 5 } keluarga & $\begin{array}{c}\text { Tidak } \\
\text { aktif }\end{array}$ & Aktif & Total & p. \\
\hline Kurang & 70 & 15 & 85 & \\
& $82.4 \%$ & $17.6 \%$ & $100.0 \%$ & \\
Cukup & 11 & 31 & 42 & 0.000 \\
& $26.2 \%$ & $73.8 \%$ & $100.0 \%$ & \\
Total & 81 & 46 & 127 & \\
& $63.8 \%$ & $36.2 \%$ & $100.0 \%$ & \\
\hline Sumber: Data primer Tahun 2020 &
\end{tabular}

Berdasarkan hasil penilaian pengaruh antara dukungan kader keluarga dengan keaktifan kunjungan Posbindu PTM di wilayah kerja Puskesmas Baturube bahwa dari 85 responden dengan dukungan keluarga yang kurang yang tidak aktif melakukan kunjungan 70 responden $(82.4 \%)$ dan yang aktif melakukan kunjungan sebanyak 15 responden (17.6\%), sedangakan pada 42 responden dengan dukungan keluarga yang cukup yang tidak aktif melakukan kunjungan sebanyak 11 responden (26.2\%) dan yang aktif melakukan kunjungan sebanyak 31 responden (73.8\%). Hasil uji bivariat dengan menggunakan uji chi square dengan alternative Uji fisher menunjukan bahwa nilai $\mathrm{p}=0,000<0,05$ yang artinya ada hubungan yang signifikan antara dukungan keluarga dengan keaktifan kunjungan Posbindu PTM di wilayah kerja Puskesmas Baturube.

\begin{tabular}{ccccc}
\hline $\begin{array}{c}\text { Perilaku } \\
\text { petugas } \\
\text { kesehat } \\
\text { an }\end{array}$ & \multicolumn{4}{c}{ Keaktifan Kunjungan } \\
\cline { 2 - 5 } & $\begin{array}{c}\text { Tidak } \\
\text { aktif }\end{array}$ & Aktif & Total & $\boldsymbol{p}$. \\
\hline Kurang & 8 & 2 & 10 & \\
& $80.0 \%$ & $20.0 \%$ & $100.0 \%$ & \\
Cukup & 73 & 44 & 117 & 0.000 \\
& 62.4 & 37.6 & $100.0 \%$ & \\
Total & 81 & 46 & 127 & \\
& $63.8 \%$ & $36.2 \%$ & $100.0 \%$ & \\
\hline
\end{tabular}

Sumber: Data primer Tahun 2020

Berdasarkan hasil penilaian pengaruh antara perilaku petugas kesehatan dengan keaktifan kunjungan Posbindu PTM di wilayah kerja Puskesmas Baturube bahwa dari 10 responden yang menyatakan perilaku petugas kesehatan kurang baik yang tidak aktif melakukan kunjungan sebanyak 8 responden $(80.0 \%)$ dan aktif sebanyak 2 responden (20.0\%), sedangkan pada 117 responden yang menyatakan perilaku petugas kesehatan baik yang tidak aktif melakukan sebanyak 73 responden (62.4\%) dan yang aktif melakukan kunjungan sebanyak 44 responden (37.6\%). Hasil uji bivariat dengan menggunakan uji chi square dengan alternative Uji fisher menunjukan bahwa nilai $\mathrm{p}=0,226>0,05$ yang artinya tidak ada hubungan antara perilaku petugas kesehatan dengan keaktifan kunjungan Posbindu PTM di wilayah kerja Puskesmas Baturube. 


\section{Analisis Multivariat}

Tabel 8. Pengaruh Pengetahuan, Jarak, Dukungan Kader dan Dukungan Keluarga dengan Keaktifan Kunjungan Posbindu PTM di Wilayah Kerja Puskesmas Baturube

\begin{tabular}{l|c|c|c|c|c}
\hline \multicolumn{1}{c|}{ Model } & \multicolumn{2}{|c|}{ Underdized Coefficients } & $\begin{array}{c}\text { Standardized } \\
\text { Coefficients }\end{array}$ & & \\
\cline { 1 - 4 } & $\mathrm{B}$ & Sttd.Error & Beta & $\mathrm{t}$ & Sig. \\
\hline (Constant) & .055 & .122 & & .453 & .651 \\
Pengetahuan & .115 & .049 & .172 & 2.327 & .022 \\
Jarak & .228 & .088 & .182 & 2.580 & .011 \\
Dukungan kader & .297 & .074 & .297 & 4.042 & .000 \\
Dukungan keluarga & .347 & .070 & .340 & 4.926 & .000 \\
\hline
\end{tabular}

Berdasarkan persamaan regresi pada tabel 8, nilai konstanta positif sebesar 0.055 menunjukkan pengaruh positif variabel independen (pengetahuan, jarak, dukungan kader, dukungan keluarga). Bila variabel independent naik atau berpengaruh dalam satu satuan, maka variabel keaktifan kunjungan Posbindu PTM akan mengalami peningkatan.

Koefisien regresi pengetahuan terhadap keaktifan kunjungan Posbindu PTM sebesar 0.115, koefisien regresi jarak terhadap keaktifan kunjungan Posbindu PTM sebesar 0.228, koefisien regresi dukungan kader terhadap keaktifan kunjungan Posbindu PTM sebesar 0.297 dan koefisien regresi dukungan keluarga terhadap keaktifan kunjungan Posbindu PTM sebesar 0.347.

Dari hasil output ini $\mathrm{t}$ hitung untuk pengetahuan sebesar 2.327 dan nilai signifikansinya $0.022<0.05$, t hitung jarak sebesar 2.580 dan nilai signifikansinya $0.011<0.05$, $\mathrm{t}$ hitung dukungan kader sebesar 4.042 dan nilai signifikansinya $0.000<0.05$, t hitung dukungan keluarga sebesar 4.926 dan nilai signifikansinya 0.000< 0.05, maka dapat diambil kesimpulan bahwa pengetahuan, jarak, dukungan kader dan dukungan keluarga secara parsial atau sendiri-sendiri mempunyai pengaruh yang signifikan terhadap keaktifan kunjungan Posbindu PTM.

Dari hasil output nilai Beta untuk pengetahuan sebesar 0.172, jarak sebesar 0.182, dukungan kader sebesar 0.297, dan dukungan keluarga sebesar 0.340. Karena nilai Beta untuk dukungan keluarga lebih besar yaitu 0.340 maka dapat disimpulkan bahwa dukungan keluarga mempunyai pengaruh dominan terhadap keaktifan kunjungan Posbindu PTM.

\section{PEMBAHASAN}

Pengaruh Pengetahuan terhadap Keaktifan Kunjungan Posbindu PTM di Wilayah Kerja Puskesmas Baturube

Pengetahuan merupakan salah satu faktor instrinsik yang mempengaruhi motivasi. Pengetahuan merupakan hasil dari tahu, dan ini terjadi setelah orang melakukan penginderaan terhadap suatu objek tertentu (Notoatmodjo 2007). Permintaan akan pelayanan kesehatan bergantung dari pengetahuan mengenai apa yang ditawarkan dalam pelayanan tersebut, 
bagaimana serta kapan dan oleh siapa serta dengan biaya berapa. Pengetahuan sendiri merupakan hasil dari tahu dan ini terjadi setelah melakukan penginderaan terhadap suatu objek tertentu. Pengetahuan merupakan domain yang sangat penting dalam membentuk tindakan seseorang (Notoatmodjo, 2003). Sebelum seseorang mengadopsi perilaku, ia harus tahu terlebih dahulu apa arti atau manfaat perilaku tersebut bagi dirinya, termasuk dalam perilaku pemanfaatan pelayanan kesehatan. (Notoatmodjo, 2003).

Berdasarkan hasil penilaian pengaruh antara pengetahuan dengan keaktifan kunjungan Posbindu PTM di wilayah kerja Puskesmas Baturube bahwa hasil uji bivariat dengan menggunakan uji chi square dengan alternative Uji fisher menunjukan bahwa nilai $\mathrm{p}=0,000<0,05$ yang artinya ada pengaruh yang signifikan antara pengetahuan dengan keaktifan kunjungan Posbindu PTM di wilayah kerja Puskesmas Baturube.

Hasil penelitian ini sejalan dengan penelitian Ivong (2017) yang menyatakan bahwa responden yang memiliki pengetahun kurang mempunyai kecenderungan untuk aktif berkunjung ke Posbindu PTM sebesar 4.9 kali dibandingkan dengan yang berpengetahuan baik. Hasil dari penelitian ini sesuai dengan penjelasan teori bahwa pengetahuan sangat erat dikaitkan dengan tingkat pendidikan, dimana diharapkan bahwa orang yang berpendidikan tinggi akan mempunyai pengetahuan yang luas. Akan tetapi perlu ditekankan bahwa pengetahuan seseorang bukan hanya diperoleh melalui pendidikan formal saja namun juga dapat diperoleh dari pendidikan tidak formal (Wawan dan Dewi, 2010),
Hasil penelitian yang sama juga dilakukan oleh Dwi dan Mieke (2018) menyatakan bahwa responden berpengetahuan tinggi mempunyai peluang 2,553 kali lebih aktif memanfaatkan Posbindu PTM dibandingkan dengan responden berpengetahuan rendah dalam memanfaatkan Posbindu PTM. Teori Lawrenca Green yang menjelaskan pengetahuan yang kurang baik tentang Posbindu PTM cenderung kurang baik dalam praktik kunjungan ke posbindu.

Sebagian besar responden kurang memahami siapa saja sasaran kegiatan Posbindu PTM dan manfaat yang didapatkan dengan adanya Posbindu PTM. Hal ini menunjukkan bahwa informasi yang didapatkan masyarakat masih sangat kurang. Bahkan beberapa responden menyatakan hanya mengetahui tentang adanya pemeriksaan kesehatan gratis, padahal yang dimaksud dalam hal itu adalah Posbindu PTM. Kurangnya sosialisasi ataupun informasi mengenai manfaat Posbindu PTM tentu mempengaruhi motivasi masyarakat untuk melakukan kunjungan. Predisposisi yang terwujud dalam pengetahuan ini adalah kurangnya pengetahuan responden, keluarga serta masyarakat tentang posbindu baik dalam memahami dan mengetahui tujuan dan adanya kegiatan posbindu menyebabkan keaktifan kunjungan Posbindu oleh masyarakat akan berkurang.

Perubahan jadwal posbindu juga menjadi faktor yang mempengaruhi masyarakat tidak melakukan kunjungan ke posbindu meskipun memiliki pengetahuan yang baik. Beberapa sampel tidak mengetahui adanya perubahan jadwal yang sewaktu- waktu berubah. 
Jarak terhadap Keaktifan Kunjungan Posbindu PTM di Wilayah Kerja Puskesmas Baturube

Berdasarkan hasil penilaian pengaruh antara jarak dengan keaktifan kunjungan Posbindu PTM di wilayah kerja Puskesmas Baturube bahwa hasil uji bivariat dengan menggunakan uji chi square dengan alternative Uji fisher menunjukan bahwa nilai $\mathrm{p}=0,000<0,05$ yang artinya ada pengaruh yang signifikan antara jarak dengan keaktifan kunjungan Posbindu PTM di wilayah kerja Puskesmas Baturube.

Jarak adalah ukuran jauh dekatnya antara tempat yang satu dengan yang lainnya dan diukur dengan status meter. Jarak tempat tinggal dapat menjadi faktor pendorong karena jauh dekatnya jarak dapat mempengaruhi seseorang dalam melakukan aktivitas. Semakin jauh jarak yang ditempuh seseorang dari tempat tinggal ke pelayanan kesehatan maka semakin banyak waktu yang dikeluarkan. Semakin jauh jarak tempat tinggal dengan pelayanan kesehatan akan semakin menurunnya motivasi seseorang untuk berkunjung ke pelayanan kesehatan (nasruddin,2017).

Sejalan dengan hasil penelitian yang dilakukan oleh Retno dan Brigita (2013) yang mendapatkan hasil uji statistik di dapatkan $\mathrm{p}$ value $<0.05$ yaitu 0.010 . Maka dengan demikian hipotesis nol (Ho) ditolak dan yang berlaku hipotesis alternatif (Ha). Dapat disimpulkan bahwa faktor jarak rumah ke lokasi posbindu berhubungan dengan kehadiran lansia ke Posbindu.

Hasil penelitian Dwi dan Mieke (2018) juga memperoleh nilai Odds Ratio (0R) sebesar 2,784, artinya akses yang mudah mempunyai peluang 2,784 kali lebih besar menjadikan responden lebih aktif memanfaatkan Posbindu PTM dibandingkan dengan responden yang memiliki akses sulit, tidak aktif memanfaatkan Posbindu. Hasil penelitian Ivong (2017) menunjukkan bahwa keaktifan kunjungan Posbindu PTM di Desa Bulupitu lebih baik pada responden yang jarak Posbindu PTM tidak jauh dari rumah dibandingkan dengan yang jauh jaraknya dari rumah. Analisis lebih lanjut di dapatkan nilai $\mathrm{p}=0.034$, yang berarti ada hubungan yang bermakna antara jarak dengan keaktifan kunjungan Posbindu PTM.

Dalam penelitian ini peneliti melakukan wawancara rengan sampel mengenai jarak rumah yang menyebabkan sampel tersebut tidak aktif melakukan kunjungan pada kegiatan Posbindu PTM. Beberapa sampel menyatakan karena jarak rumahnya yang terlalu jauh dengan tempat dilaksanakannya Posbindu PTM, maka dibutuhkan waktu dan kendaraan untuk menjangkau tempat tersebut. Mereka menyatakan ada yang tidak memiliki kendaraan, ada yang tidak bisa mengendarai sepeda motor sendiri dan harus diantarkan keluarganya. Karena keluarganya yang terlalu sibuk dengan pekerjaan bertani akan menghambat sampel untuk aktif melakukan kunjungan pada kegiatan Posbindu PTM. Beberapa sampel yang memiliki jarak dekat namun tidak aktif melakukan kunjungan pada kegiatan Posbindu PTM hal ini dikarenakan mereka memiliki pekerjaan yang sulit ditinggalkan jadi mereka lebih memilih bekerja karena mereka menganggap untuk pemeriksaan kesehatan seperti pemeriksaan tekanan darah, gula, kolesterol, dan asam urat bisa dilakukan di Poskesdes jika mereka merasa kurang sehat akan menghambat responden untuk aktif melakukan kunjungan pada kegiatan Posbindu PTM. 
Sedangakan beberapa responden yang memiliki jarak rumah jauh dan aktif melakukan kunjungan pada kegiatan Posbindu PTM hal itu dikarenakan mereka mengetahui manfaat dari posbindu bisa mengendarai sepeda motor dan memiliki kendaraan sendiri sehingga mereka rela meninggalkan pekerjaannya demi kesehatannya.

\section{Pengaruh Dukungan Kader terhadap Keaktifan Kunjungan Posbindu PTM di Wilayah Kerja Puskesmas Baturube}

Berdasarkan Direktorat Bina Peran

Serta Masyarakat Depkes RI memberikan batasan bahwa kader adalah warga masyarakat setempat yang dipilih dan ditinjau oleh masyarakat dan dapat bekerja secara sukarela. Peran kader dalam kegiatan posbindu yaitu berperan aktif dalam kegiatan posbindu dan mengajak masyarakat untuk aktif dalam kegiatan tersebut.

Hasil penilaian pengaruh antara dukungan kader dengan keaktifan kunjungan Posbindu PTM di wilayah kerja Puskesmas Baturube bahwa hasil uji bivariat dengan menggunakan uji chi square dengan alternative Uji fisher menunjukan bahwa nilai $\mathrm{p}=0,000<0,05$ yang artinya ada pengaruh yang signifikan antara dukungan kader dengan keaktifan kunjungan Posbindu PTM di wilayah kerja Puskesmas Baturube.

Sejalan dengan penelitian yang dilakukan oleh Purdiyani (2016), hasil analisis hubungan antara dukungan kader kesehatan dengan pemanfaatan Posbindu PTM menunujukkan nilai $\mathrm{p}$-value sebesar 0,000. Karena nilai $\mathrm{p}<0,05$ maka dapat ditarik kesimpulan, Ho ditolak. Artinya ada hubungan antara dukungan kader kesehatan dengan pemanfaatan Posbindu PTM oleh wanita lansia. Dalam teori yang dikemukakan oleh Lawrence Green menyatakan bahwa kader kesehatan merupakan salah satu faktor pendukung yang berperan dalam perilaku kesehatan karena merupakan faktor penyerta yang berperan bagi menetap atau lenyapnya suatu perilaku.

Hasil penelitian Dwi dan Mieke (2018) menunjukkan hasil uji Chi-Square diperoleh p-value sebesar 0,000 yang berarti ada hubungan antara dukungan kader dengan pemanfaatan Posbindu PTM di wilayah kerja Puskesmas Kecamatan Setiabudi Kota Jakarta Selatan. Diperoleh nilai Odds Ratio (OR) sebesar 6,970, artinya responden yang mendapat dukungan dari kader mempunyai peluang 6,970 kali lebih besar untuk aktif memanfaatkan Posbindu PTM dibandingkan dengan responden yang tidak mendapat dukungan kader. Sedangkan hasil penelitian yang dilakukan oleh Mardiyanti, dkk (2019) menyatakan hasil penelitian masuk dalam isyarat bertindak dimana teori HBM menjelaskan bahwa secara terpisah isyarat bertindak meningkatkan penerimaan-penerimaan mengenai persepsi untuk melakukan tindakan, yang dalam hal ini pemanfaatan Posbindu PTM.

Dari hasil wawancara terhadap beberapa responden dalam penelitian ini sebagian besar responden menyatakan tidak pernah mendapatkan sosialisasi maupun informasi mengenai Posbindu PTM dari tenaga kesehatan maupun kader. Diperlukan peran petugas kesehatan secara terus menerus dan berkesinambungan dalam melakukan pendekatan dan memberikan informasi kesehatan kepada masyarakat. Kurangnya inisiatif kader dalam mengajak masyarakat untuk memeriksakan kesehatannya di posbindu menyebabkan kurangnya pula motivasi 
masyarakat untuk berkunjung. Hal ini menyebabkan perlunya monitoring dan evaluasi terhadap pelaksanaan posbindu sehingga kualitas pelayanannya menjadi lebih baik.

\section{Pengaruh Dukungan Keluarga terhadap Keaktifan Kunjungan Posbindu PTM di Wilayah Kerja Puskesmas Baturube}

Berdasarkan hasil penilaian pengaruh antara dukungan keluarga dengan keaktifan kunjungan Posbindu PTM di wilayah kerja Puskesmas Baturube bahwa hasil uji bivariat dengan menggunakan uji chi square dengan alternative Uji fisher menunjukan bahwa nilai $\mathrm{p}=0,000<0,05$ yang artinya ada pengaruh yang signifikan antara dukungan keluarga dengan keaktifan kunjungan Posbindu PTM di wilayah kerja Puskesmas Baturube.

Dukunggan keluarga menurut Friedman (1998) dalam Krisnawati (2010) dukungan keluarga adalah sikap, tindakan dan penerimaan keluarga terhadap penderita yang sakit maupun yang sehat. Perilaku seseorang dalam mengikuti Posbindu PTM sangat efektif bila didukung oleh situasi sosial yang baik. Keluarga, teman dekat, teman kerja dan lingkungan sekitar merupakan komponen penting dari terbentuknya perilaku seseorang mengikuti pelayan kesehatan dalam Posbindu PTM (Trihardini, 2007).

Sejalan dengan penelitian yang dilakukan Syafii, dkk (2016) lansia dengan dukungan keluarga baik dapat mempengaruhi kondisi dan perilaku lansia yang bersifat positif dalam hal ini kehadiran lansia mengikuti Posbindu PTM, sedangkan dukungan keluarga kategori kurang dapat mempengaruhi kondisi dan perilaku yang bersifat negatif yaitu lansia kurang mengerti dan paham, mengenai kegiatan Posbindu PTM dan mengakibatkan kurangnya kehadiran dalam kegiatan Posbindu PTM.

Hasil penelitian ini sesuai dengan penelitian yang dilakukan Umayana, dkk (2015) penelitian ini menunjukkan bahwa dukungan keluarga yang kurang dapat menurunkan keaktifan penduduk ke Posbindu PTM sebaliknya, dukungan keluarga yang kurang dapat meningkatkan keaktifan penduduk ke Posbindu PTM. Peran keluarga juga dapat meningkatkan informasi pada penduduk tentang pentingnya posbindu, sehingga anggota keluarga lain juga dapat berprtisipasi dalam pemeriksaan kesehatan di Posbindu PTM secara rutin (Lestari,2011).

Dukungan keluarga yang rendah tersebut disebabkan karena anggota keluarga yang bekerja sehingga kurang memperhatikan pentingnya pemeriksaan kesehatan dalam upaya pencegahan penyakit (Sunartyasih, 2012). Hal ini didukung ketika peneliti melakukan wawancara dengan responden mengenai dukungan keluarga. Beberapa responden keluarganya lupa untuk menginformasikan kapan jadwal akan diadakannya Posbindu PTM, dan beberapa responden menyatakan bahwa keluarga mereka tidak bersedia mengantarkan ke tempat Posbindu PTM dengan alasan pekerjaan yang tidak bisa ditinggalkan. Beberapa responden yang yang memiliki dukungan keluarga tinggi dan tidak aktif melakukan kunjungan pada kegiatan Posbindu PTM, hal ini dikarenakan responden memilih untuk memeriksakan kesehatannya di Poskesdes dengan alasan lebih dekat. Sedangkan beberapa responden yang memiliki dukungan keluarga rendah dan aktif melakukan kunjungan ke Posbindu PTM hal ini dikarenakan responden memiliki motivasi diri yang tinggi. Mereka bersedia 
datang ke tempat Posbindu PTM sendiri tanpa harus diantar keluarganya.

\section{UCAPAN TERIMA KASIH}

Penulis ingin mengucapkan terima kasih kepada Pascasarjana Universitas Muslim Indonesia, Puskesmas Baturube atas dukungan terhadap penelitian ini.

\section{KESIMPULAN}

Dukungan keluarga memiliki peran yang sangat signifikan bagi masyarakat sasaran posbindu untuk aktif dalam melakukan kunjungan ke Posbindu PTM. Diharapkan keluarga dapat memberikan dukungan informasional, dukungan penilaian, penghargaan, dukungan instrumental dan dukungan emosional terhadap masyarakat sasaran posbindu agar masyarakat selalu termotivasi untuk aktif melakukan kunjungan Posbindu PTM. Pemberdayaan keluarga untuk meningkatkan keaktifan kunjungan dalam pelaksanaan Posbindu PTM menarik untuk dijadikan penelitian selanjutnya.

\section{DAFTAR PUSTAKA}

1. Ali, 2010. Pengantar Keperawatan Keluarga. Jakarta : EGC.

2. Andersen, R and Newman, J. 2005. Societal and Individual Determinants of Medical Care Utilization in the United States. The Milkbank Quarterly, 83 (4).

3. Ariani, A. P. (2014). Aplikasi Metodologi Penelitian Kebidanan Dan Kesehatan Reproduksi. Yogyakarta: Nuha Medika.

4. Astuti, Emy Dwi. (2016). Gambaran Proses Kegiatan Pos Pembinaan Terpadu Penyakit Tidak Menular di Puskesmas Sempu Kabupaten Banyuwangi. e-juornal Pustaka Kesehatan Volume 4, No.2.
5. Bustan. Epidemiologi Penyakit Tidak Menular. Jakarta: Rineka Cipta, 2007.

6. Dahlan, M. Sopiyudin. Statistik Untuk Kedokteran dan Kesehatan. Jakarta: .2014

7. Depkes RI. Pedoman Surveilans Penyakit Jantung dan Pembuluh Darah. Jakarta: Departemen Kesehatan RI, 2007.

8. Donsu, J. D. (2016). Metodologi Penelitian Keperawatan. Yogyakarta: Pustaka Baru Press.

9. Fuadah Dina Zakiyyatul. (2018). Pemanfaatan Pos Pembinaan Terpadu (Posbindu) Penyakit Tidak Menular (PTM pada Penderita Hipertensi. Jurnal Ners dan Kebidanan, Volume 5, No.1.

10. Hasanah Uswatun. (2018). Efektifitas Senam Prolanis Terhadap Penderita Hipertensi dan Diabetes Mellitus Tipe II di Wilayah Kerja Puskesmas Teppo Kecamatan Patampanua Kabupaten Pinrang Tahun 2018.

11. Harnilawati. 2013. Konsep dan Proses Keperawatan Keluarga. Takalar : PT As Salam.

12. Irianto, K. (2014). Epidemiologi Penyakit Menular dan Tidak Menular. Bandung: Alfabeta

13. Irwan. (2016). Epidiomologi Penyakit Tidak Menular. Yogyakarta : Depublish

14. Karen G, Rimer B, Viswanath. The Health Belief Model. In : Health Behaviour and Health Education.4th ed. United State of America : JosseyBass A Wiley Imprints;2008.

15. Kemenkes RI. Petunjuk Teknis Pos Pembinaan Terpadu Penyakit Tidak Menular (POSBINDU PTM), 2012.

16. Petunjuk Teknis Surveilans Faktor Risiko Penyakit Tidak Menular 
Berbasis Pos Pembinaan Terpadu (POSBINDU),2014.

17. Profil Kesehatan Indonesia Tahun 2013,2013.

18. Kitting Pah Renate. (2015). Faktor Yang Berhubungan Dengan Kinerja Kader Posbindu Penyakit Tidak Menular. Jurnal Berkala Kesehatan, Volume 1, No.2 Mei 2016 : 106-114.

19. Kresnawati \& Kartinah. 2010. Hubungan Dukungan Keluarga Dengan Keaktifan Lansia (Lanjut Usia) Dalam Mengikuti Kegiatan di Posyandu Lansia di Desa Gonilan Kecamatan Surakarta.

20. Kurnia, Arininda Rima. Analisis Faktor-faktor yang Berhubungan dengan Kunjungan Masyarakat Usia Produktif (15-64 tahun) di Posbindu PTM Puri Praja Wilayah Kerja Puskesmas Mulyoharjo, Pemalang. Skripsi, FKM Undip. Semarang, 2017.

21. Lawrence W Green. 2005. Health Program Planning ab Educational and Ecological Approach. New York ; McGraw-Hill Companies.

22. Liansyah, Wahyu., Puput Oktamanti. Faktor-faktor yang Berhubungan dengan Pemanfaatan Pelayanan Posbindu Lansia di Wilayah Kerja Puskesmas Beji Tahun 2014.

23. Mardhiyanti Ika. (2019). FaktorFaktor Yang Berhubungan Dengan Pemanfaatan Posbindu PTM di Puskesmas Rowosari Kota Semarang. Jurnal Kesehatan Masyarakat, Volume 7, No.3 (ISSN : 2356-3346 ).

24. Masriadi. 2016. Epidemiologi Penyakit Tidak Menular.jakarta. Cv. Trans Info Media.
25. Muh Rosid Syafii, S. H. (2015). Hubungan antara dukungan keluarga dengan keaktifan lansia (Lanjut usia) mengikuti pos pembinaan terpadu penyakit tidak menular 9Posbindu PTM) di Desa Jelbuk Kecamatan Jelbuk Kabupaten Jember.

26. Nasruddin Rayhana Nurizka. (2017). Faktor-Faktor Yang Mempengaruhi Pemanfaatn Po Pembinaan Terpadu Penyakit Tidak Menular (Posbindu PTM) Di Wilayah Kerja Puskesmas Ballaparang Kota Makassar.

27. Notoatmodjo. 2012. Metodologi Penelitian Kesehatan- Ed. Rev.Jakarta: Rineka Cipta, 2012.

28. -------. Ilmu Kesehatan Masyarakat. Prinsip-Prinsip Dasar. Jakarta: Rineka Cipta, 2003.

29. -------. Kesehatan Masyarakat: Ilmu dan Seni. Jakarta: Rineka Cipta, 2007.

30. ---------. Promosi Kesehatan Teori dan Aplikasi. Jakarta: Rineka Cipta, 2005.

31. Nuraini Bianti. 2015. Risk factors of hypertension. Faculty of medicine, university of lampung.

32. Nursalam. (2016). Metodologi Penelitian Ilmu Keperawatan Edisi 4. Jakarta: Salemba Medika.

33. Purdiyani Fauzia. (2016). Pemanfaatan Pos Pembinaan Terpadu Penyakit Tidak Menular (Posbindu PTM) oleh Wanita Lansia Dalam Rangka Mencegah Penyakit Tidak Menular di Wilayah Kerja Puskesmas Cilongok 1. Jurnal Kesehatan Masyarakat, Volume 4, No.1 (ISSN : 2356-3346 ).

34. Remais JV, Guang Z, dan Guangwei L. Convergence of Noncommunicable and Infectious Diseases in Low and Middle Income 
Countries. International Journal of Epidemiology. (42) :221-227, 2012.

35. RISKESDAS. Riset Kesehatan Dasar RISKESDAS 2013. Jakarta: Badan

Penelitian dan Pengembangan

Kesehatan Kementerian Kesehatan RI, 2013.

36. Rusdiyanti Ivong. (2017). FaktorFaktor yang Mempengaruhi Keaktifan Kunjungan Pos Pembinan Terpadu Penyakit Tidak Menular di Desa. Healthy-Mu Juornal Volume 1, No.2.

37. Setiadi, Nugroho J. Perilaku Konsumen. Bandung: Prenada Media, 2005.

38. Shilton T., Beatriz C., \& Claire B. Towards a Global Framework for Capacity Building for Noncommunicable Disease Advocacy in Low and Middle Income Countries. Global Health Promotion Journal, 20 (4), 2013.

39. Triwibowo, C., \& Pusphandani, M. E. (2015). Pengantar Dasar Ilmu kesehatan masyarakat. Yogyakarta: Nuha Medika.

40. Umayana Try Haniek. (2015). Dukungan Keluarga dan Tokoh Masyarakat Terhadap Keaktifan Penduduk ke Posbindu Penyakit Tidak Menular. Jurnal Kesehatan Masyarakat, ISSN : 1858-1196.

41. Warganegara Efrida. (2016). Faktor Risiko Perilaku Penyakit Tidak Menular. Majority Volume 5, No.2.

42. WHO. Global Status report on noncommunicable Disease 2014. World Health, p.176, 2017 